\title{
ASSOCIATION BETWEEN THROMBUS IMAGING FEATURES ON CT AND CLINICO-RADIOLOGICAL OUTCOME IN PATIENTS WITH MIDDLE CEREBRAL ARTERY ACUTE ISCHEMIC STROKE TREATED WITH MECHANICAL THROMBECTOMY
}

Sotelo Harol, MD | Serra Mercedes, MD | Pfister Pablo, MD | Hernández Jairo, MD | Chaves Hernán, MD | Cejas Claudia, MD. FLENI, Buenos Aires, Argentina

INTRODUCTION

Diagnostic imaging methods have been used to determine qualitative and quantitative parameters of cerebral thrombus in the setting of stroke. The aim of our work is to establish if there is a correlation between intrinsic thrombus features on computed tomography (CT) with reperfusion and functional outcome in patients with acute ischemic stroke who underwent mechanical thrombectomy (MT).

\section{MATERIALS AND METHODS}

We retrospectively searched for consecutive patients in our database between January 2015 and December 2019. We included patients over 18 of age, clinical suspicion of stroke and treated with MT. We excluded patients without CT previous to MT and patients with non-middle cerebral artery (MCA) stroke.

Imaging features evaluated included thrombus location (M1, M2 and/or M3 segments), thrombus density (in Hounsfield units, $\mathrm{HU}$ ) and thrombus length $(<5,5$ to 10 and $>10 \mathrm{~mm}$ )

Outcome was evaluated with the modified Treatment in Cerebral Ischemia score (mTICl) and modified Rankin Scale (mRS) at 90 days. Successful reperfusion was defined as $\mathrm{mTICl}$ scores $2 \mathrm{~b}$ or higher. Good functional outcome (FO) was defined as an $\mathrm{mRS}$ between 0 and 2 .

\section{IMAGING ANALYSIS}
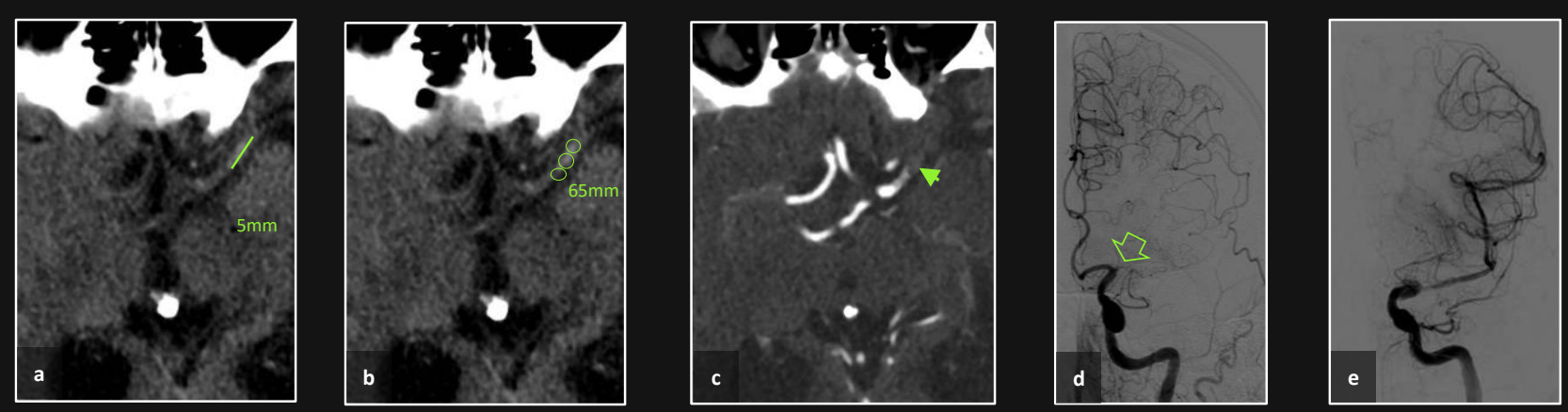

FIGURE. Imaging processing. 80yo man NCCT, showing length (a) and density(b) of thrombi in left middle cerebral artery. Intracranial Angio-CT (c) indicate focal filling defect (arrowhead) on left M1 segment. DSA exhibit thrombi occlusion (d) and postrombectomy imaging (e) showing Grade2b mTICl score whit partial filling (50-99\%) of the vascular territory.
RESULTS

12 subjects were included, 8 had successful reperfusion and 9 had good FO. Subjects with good FO were slightly younger (mean: $72 \mathrm{y} / \mathrm{o}$ ) than subjects with bad FO (mean: $77 \mathrm{y} / \mathrm{o}$ ). Mean thrombus density was $55 \mathrm{HU}$ in successful reperfusion subjects and $66 \mathrm{HU}$ in unsuccessful reperfusion subjects. Mean thrombus density was $59.5 \mathrm{HU}$ in good FO subjects and $56.3 \mathrm{HU}$ in bad FO subjects. In subjects with successful reperfusion, thrombus length was $<5 \mathrm{~mm}$ in $62,5 \%, 5$ to $10 \mathrm{~mm}$ in $12,5 \%$ and $>10 \mathrm{~mm}$ in $25 \%$, and in subjects with unsuccessful reperfusion, thrombus length was < $5 \mathrm{~mm}$ in $50 \%, 5$ to $10 \mathrm{~mm}$ in $25 \%$ and > $10 \mathrm{~mm}$ in $25 \%$. Thrombus was located on M1 in $75 \%$ of subjects and on $M 2$ in $25 \%$ of subjects in both successful and unsuccessful reperfusion groups.

Thrombus characteristics on $\mathrm{CT}$ have been positively correlated with outcome after reperfusion in patients with stroke. However, we found no statistically significant differences in reperfusion (measured by $\mathrm{mTICl}$ ) and/or functional (measured by $\mathrm{mRS}$ at 90 days) outcome. Further work should be done to clarify these contrasting results.

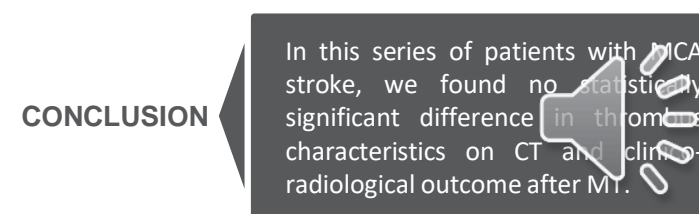

